\title{
REGRESSÃO QUANTÍLICA: UMA ANÁLISE PARA A GERAÇÃO DE ENERGIA EÓLICA E VELOCIDADE DO VENTO
}

\author{
Soraida Aguilar \\ Pontifícia Universidade Católica do Rio de Janeiro - PUC-Rio \\ Departamento de Engenharia Industrial \\ saguilar@ele.puc-rio.br \\ Reinaldo Castro Souza \\ Pontifícia Universidade Católica do Rio de Janeiro - PUC-Rio \\ Departamento de Engenharia Industrial \\ reinaldo@puc-rio.br
}

\begin{abstract}
RESUMO
Atualmente, a velocidade do vento é uma fonte de energia renovável que desempenha um papel muito importante para mitigar o impacto do consumo de energia de duas maneiras: redução de combustíveis fósseis e contribuição para a confiabilidade dos sistemas de energia elétrica. Diferentes abordagens têm sido usadas para fornecer previsões de energia eólica pois, para uma determinada velocidade do vento, a geração eólica pode representar valores diferentes, o que implica uma relação estocástica entre a velocidade do vento e a produção eólica. Neste trabalho é utilizada uma análise baseada em regressão quantílica, a qual permite abordar esta dificuldade. Para isso, as previsões de energia eólica são obtidas usando dados de um parque eólico no Brasil para validar o modelo proposto. Os resultados são encorajadores e mostram que o modelo é robusto e eficiente pois a sua estimação via otimização não requer que seja considerada hipótese nenhuma sobre a distribuição dos erros.
\end{abstract}

Palavra-chave: Velocidade do Vento; Geração Eólica; Previsão; Regressão Quantílica.

\begin{abstract}
Wind speed is currently a renewable energy source that plays a very important role in mitigating the impact of energy consumption in two aspects: reducing fossil fuels and contributing to the reliability of electricity systems. Different approaches have been used to provide wind energy forecasts, since for a given wind speed, wind generation might take different values, which implies a stochastic relationship between wind speed and wind production. In this work an analysis based on quantile regression is used, which allows to address this difficulty. For this, wind energy predictions are obtained using data from a wind farm in Brazil to validate the proposed model. The results are encouraging and show that the model is robust and efficient because its estimation via optimization does not require any hypothesis about the errors distribution.
\end{abstract}

Keywords: Wind Speed; Wind Power Generation; Forecasting; Quantile Regression.

\section{Como Citar:}

AGUILAR, Soraida; SOUZA CASTRO, Reinaldo. Regressão quantílica: uma análise para a geração de energia eólica e a velocidade do vento. In: SIMPÓSIO DE PESQUISA OPERACIONAL E LOGÍSTICA DA MARINHA, 19., 2019, Rio de Janeiro, RJ. Anais [...]. Rio de Janeiro: Centro de Análises de Sistemas Navais, 2019. 


\section{INTRODUÇÃO}

Em 2018 a energia eólica cresceu em termos globais 9\%, atingindo uma capacidade instalada de $51.3 \mathrm{GW}$, e tornando-se atualmente, para muitos mercados, uma das fontes de eletricidade mais econômicas. Em conjunto com este crescimento, uma das fortes conquistas em matéria de uso de fontes alternativas se deve a que pela primeira vez a capacidade eólica instalada superou a nova capacidade de combustíveis fósseis, tanto em mercados emergentes quanto em mercados maduros; o que implica uma redução de combustíveis fósseis e uma contribuição para a confiabilidade como resposta à consciência social e as políticas que a maioria dos países está adotando ao delinear suas estratégias energéticas [1].

Atualmente reduzir as emissões dos gases de efeito estufa tem-se tornado um dos grandes desafios, devido à escassa modelagem fisicamente realista das transformações energéticas e econômicas necessárias para este propósito. Apesar de diversos países adotarem metas para reduções profundas das emissões de gases do efeito estufa até 2050, não é claro se serão alcançados os objetivos do Acordo Climático de Paris, já que os níveis tecnicamente viáveis de eficiência energética por si só não são suficientes. Desta forma, a energia eólica no fornecimento de energia descarbonizada representa um papel proeminente a desempenhar no concerto de estratégias de solução, abrindo oportunidades para o crescimento econômico em matéria energética e na atenção da política climática [2].

O desenvolvimento contínuo da energia eólica em todo o mundo é um pilar indispensável para apoiar a transição energética, e nessa transição o Brasil como mercado emergente, tem aproveitado os leilões efetuados nos últimos tempos para impulsionar dita transformação através dos preços ultracompetitivos contra combustíveis fósseis e nucleares. Contudo, o país conta ainda com a vantagem de poder expandir sua capacidade instalada, outorgando uma grande oportunidade aos investidores que desejem contribuir com o crescimento da capacidade de geração eólica na região.

Por outro lado, a natureza intermitente da energia eólica gera diversas dificuldades relativas à geração e a qualidade da energia da rede. Baixos valores da velocidade do vento podem desencadear uma baixa geração eólica, enquanto valores altos da velocidade podem implicar em uma desconexão com o intuito de não comprometer a segurança energética do sistema. Outro aspecto a ser considero é a aleatoriedade que caracteriza a velocidade do vento, a qual requer um tratamento estocástico que permita levar em consideração a incertezas associadas a dita variável [3]. Por outro lado, a variação temporal da velocidade do vento se caracteriza por ter para uma mesma velocidade do vento, diferentes valores de produção eólica, o que denota uma necessidade imperante de uma análise que vise recolher essa variabilidade. Diversas abordagens têm sido reportadas na literatura, sendo as mais comuns a previsão, ajuste da função distribuição, modelagem e simulação de séries temporais [4].

Nesse contexto, para analisar a incerteza associada a velocidade do vento e a produção eólica será usada a técnica de Regressão Quantílica, a qual permite analisar a associação entre a variável de resposta (geração eólica) com a variável explicativa (velocidade do vento) nos diversos quantis da distribuição condicional via optimização. Assim, pode ser obtido um mapeamento mais completo da relação da velocidade do vento sobre o comportamento da produção eólica, pois é possível determinar qual a resposta de cada quantil, ao invés de unicamente o ajuste de uma reta de regressão para a média da distribuição dos dados. A Regressão Quantílica é uma técnica desenvolvida por Koenker e Bassett [5] e dentre as múltiplas vantagens que podem ser listadas se destaca o fato de que estes modelos permitem caracterizar completamente a distribuição condicional da variável de resposta dado um conjunto de regressores, assim como a facilidade na estimação dos seus parâmetros através da representação que técnica tem via programação linear. Esta abordagem tem sido empregada nas mais diversas áreas, apresentando resultados satisfatórios nas suas aplicações oferecendo 
vantagens sobre o uso dos tradicionais modelos de Regressão Linear. Como consequência, optou-se por aplicar esta metodologia para a análise e previsão de velocidade do vento. Este trabalho encontra-se organizado em quatro seções. A seguir, na seção 2 apresenta-se uma breve descrição do modelo de Regressão Quantílica. Em seguida na seção 3, descrevem-se os resultados da modelagem e previsão da velocidade de vento no Estado da Bahia. Por fim, na seção 4 são apresentadas as principais conclusões do trabalho.

\section{REGRESSÃO QUANTÍLICA}

A função da Regressão Quantílica pode ser interpretada como sendo a soma ponderada dos desvios absolutos, permitindo caracterizar a totalidade da distribuição condicional de uma variável dependente a partir de um conjunto de regressores, obtendo informações da variável de interesse para diversos níveis da distribuição, o que torna o estudo sobre o fenômeno mais completo e informativo. Adicionalmente, a Regressão Quantílica fornece uma medida robusta de locação de forma que os coeficientes estimados não são sensíveis à presença de outliers da variável dependente. Umas das características relevantes desta metodologia é que pode ser usada quando a distribuição dos dados não é gaussiana, além de considerar o fato de que os erros possam não ter uma distribuição normal, em cujo caso os estimadores provenientes da Regressão Quantílica podem ser mais eficientes que os estimadores via Mínimos Quadrados Ordinários (MQO). Segundo Koenker e Basset [5] "Soluções diferentes para distintos quantis podem ser interpretadas como diferenças na resposta da variável dependente a mudanças nos regressores em vários pontos na distribuição condicional da variável dependente”.

Como método de estimação, a Regressão Quantílica tem como propósito analisar a resposta de variáveis "não-médias". Em outras palavras, a Regressão Quantílica estima uma reta para cada quantil de interesse, afastando-se do interesse em verificar apenas o impacto das variáveis regressoras na resposta média, como normalmente é feito em uma Regressão Linear Simples. Desta forma, e entendendo a relação da Regressão Linear e a resposta média, em otimização é possível definir o cálculo da média amostral através de um problema de programação linear que visa minimizar a soma dos resíduos ao quadrado e como solução outorga a estimação dos parâmetros do modelo. De forma semelhante, é possível definir a mediana como sendo a solução para um problema de programação linear que ao invés de minimizar a soma de resíduos ao quadrado, como no caso da média, minimiza a soma dos resíduos absolutos. Para o caso da mediana, a assimetria da função de valor absoluto linear por partes implica na existência do mesmo número de observações acima e abaixo da mediana, isto é, que a minimização da soma dos resíduos absolutos deve equacionar o número de resíduos positivos e negativos presentes. No entanto, para obter qualquer outro quantil basta só minimizar a soma dos resíduos absolutos ponderados assimetricamente, simplesmente dando pesos diferentes aos resíduos positivos e negativos.

\subsection{DEFINIÇÃO DOS QUANTIS}

Seja $X$ variável aleatória (v.a.), qualquer valor real dessa v.a. pode ser caracterizado pela sua função de distribuição acumulada, $F(x)=P(X \leq x)$. Ao considerar $0<\tau<1$, a função inversa da distribuição acumulada no ponto $\tau$, tem-se que $F^{-1}(\tau)=\inf \{x: F(x) \geq \tau\}$ é o quantil de ordem $\tau$ da v.a. $X$. Desta forma, o quantil $\tau=0.5$ correspondente à mediana pode ser definido por $F^{-1}\left(\frac{1}{2}\right)[6]$. 
Segundo Hao e Naiman [7] um quantil também pode ser considerado uma solução para um determinado problema de minimização. Para isto, seja $X$ uma v.a. e $\mu$ a média da distribuição de $x$. É possível medir o quanto um dado ponto de $X$ está distante do valor $\mu$ usando o desvio quadrado $(X-\mu)^{2}$ e, em seguida o quanto $X$ está afastado de $\mu$ em média, através do valor esperado do desvio quadrático $E(X-\mu)^{2}$. De forma similar, a mediana $m$ pode ser analisada sob esta mesma perspectiva, mas ao invés de usar uma distância quadrática pode-se medir o quanto $X$ está distante de $m$ por meio da distância absoluta $|X-m|$, e a medida da distância média na população desde $m$, por médio do valor esperado da distância absoluta $E|X-m|$. Os autores demostram que o valor de $m$ que minimiza esse valor esperado é corresponde à mediana.

A função $|X-m|$ é uma função convexa, assim que a solução da minimização desta função é encontrar um ponto em que a derivada em relação a $m$ seja zero ou onde as duas derivadas direcionais mudem de sinal. Este ponto é a mediana da distribuição. De forma análoga, para uma amostra também pode-se definir a distância média absoluta de $m$ até os pontos amostrais por: $f(m)=\frac{1}{n} \sum_{i=1}^{n}\left|x_{i}-m\right|$. A função $f$ assume um valor mínimo quando a derivada for igual a $-\frac{1}{n}$ para $m<x_{i}$ e $\frac{1}{n}$ para $m>x_{i}$. Porém, a função $f$ não é diferençável em $m=x_{i}$, assim, ela irá admitir derivada direcional de $-\frac{1}{n}$ na direção negativa e $\frac{1}{n}$ na direção positiva [7].

Este resultado pode ser generalizado para qualquer quantil de interesse, pois para qualquer $\tau \epsilon(0,1)$, a distância de $X$ para um dado $q$ é medida pela distância absoluta ponderada entre $X$ e $q$, es está definida por:

$$
d_{\tau}(X, q)=\left\{\begin{array}{cc}
(1-\tau)|X-q|, & X<q \\
\tau|X-q|, & X \geq q
\end{array}\right.
$$

O valor de $q$ que minimiza a distância média de $X$ é o $E\left[d_{\tau}(X, q)\right]$, é o $\tau$-ésimo quantil. Da mesma maneira, em uma amostra, o $\tau$-ésimo quantil é o valor de $q$ que minimiza a distância média ponderada [7]:

$$
\frac{1}{n} \sum_{i=1}^{n} d_{\tau}(X, q)=\frac{1-\tau}{n} \sum_{x_{i}<q}\left|x_{i}-q\right|+\frac{\tau}{n} \sum_{x_{i}>q}\left|x_{i}-q\right|
$$

\subsection{ESPECIFICAÇÃO DO MODELO DE REGRESSÃO QUANTÍLICA E OTIMIZAÇÃO}

Formalmente, um modelo de Regressão Quantílica possui uma relação funcional entre as variáveis regressoras e a variável de resposta, a qual pode ser descrita como [6]:

$$
Q_{\tau}(Y \mid X=x)=X^{T} \beta(\tau)=\beta_{0}(\tau)+x_{1} \beta_{1}(\tau)+x_{2} \beta_{2}(\tau)+\cdots+x_{n} \beta_{n}(\tau)+\varepsilon(\tau)
$$

Sendo $\beta_{0}$ a constante da regressão e o conjunto $\left(\beta_{1}, \beta_{2}, \ldots, \beta_{n}\right)$ os coeficientes da regressão, respectivamente; e $\tau$ refere-se ao quantil de interesse $(0<\tau<1)$. No modelo, $X$ representa o vetor das variáveis independentes, isto é, $n-1$ regressores. Além disso, $\varepsilon(\tau)$ são os erros aleatórios independentes e identicamente distribuídos, com quantil de ordem $\tau$ igual a zero. 
Na Regressão Linear Simples, os modelos estimam apenas uma reta para explicar a relação existente no grupo de dados, porém estes modelos não são muito eficientes em obter as mudanças na distribuição da variável de resposta. Para conjuntos de dados que se caracterizam por apresentar assimetria, caudas pesadas ou heterocedasticidade, o modelo de Regressão Quantílica oferece vantagens em relação a esses aspectos para a distribuição de dados ao permitir a estimação de curvas para cada um dos quantis de interesse. Desta forma as interpretações dos resultados ajustam-se melhor, já que é possível estabelecer a relação com as regiões centrais fazendo uso da mediana e das caudas da distribuição condicional [6].

Como supracitado, podemos definir os quantis através do recurso alternativo de um problema de otimização. Em Regressão Linear podemos obter uma estimativa da média populacional incondicional, $E[Y]$, através da média amostral:

$$
E[Y]=\arg \min E\left[(Y-\mu)^{2}\right]
$$

Substituindo o escalar $\mu$ da Eq. (4) por uma função paramétrica $\mu(x, \beta)$ expressão resultante é equivalente a determinar a solução para:

$$
\min _{\beta} \sum_{i=1}^{n}\left(y_{i}-\mu\left(x_{i}, \beta\right)\right)^{2}=\min _{\beta} \sum_{i=1}^{n}\left(y_{i}-x_{i}^{T} \beta\right)^{2}
$$

E assim obtém-se uma estimação do valor esperado condicional $E[Y \mid X=x]$. Já no caso dos modelos de Regressão Quantílica, utilizando a analogia da média amostral, a otimização, que é feita para cada $\tau$-ésimo quantil de $Y$, pode ser vista como:

$$
Q_{\tau}(Y)=\arg \min _{\alpha} E\left[\rho_{\tau}(\varepsilon)(Y-\alpha)\right]
$$

Sendo $\rho_{\tau}(u)$ uma função de perda definida por:

$$
\rho_{\tau}(\varepsilon)=\left\{\begin{array}{cc}
0, & \varepsilon=0 \\
\varepsilon(\tau), & \varepsilon>0 \\
\varepsilon(\tau-1) & , \quad \varepsilon<0
\end{array}\right.
$$

Esta função de perda penaliza os erros cometidos de forma diferente, o que implica que para cada quantil escolhido a penalidade aplicada para os erros que ultrapassem dito quantil é uma ponderação distinta da que que será aplicada para os erros abaixo dele. Para os erros para acima, a penalização segue a estrutura da segunda línha da função de perda na Eq. (7), enquanto que a terceira linha dessa mesma função corresponde aos erros cometidos para abaixo desse quantil. Resulta natural que quando o erro é zero, a perda também seja zero. Por tanto, a otimização do $\tau$-ésimo quantil e rescrevendo a Eq. (7) está dada por:

$$
\min _{\alpha} \sum_{i=1}^{n} \rho_{\tau}\left(y_{i}-\alpha\right)
$$


Substituindo o escalar $\alpha$ da Eq. (8), e dado que $Q_{\tau}(Y \mid X=x)=X^{T} \beta(\tau)$ na Eq. (3), as estimativas para os betas são dadas por:

$$
\hat{\beta}(\tau)=\arg \min _{\beta} \sum_{i=1}^{n} \rho_{\tau}\left(y_{i}-x_{i}^{T} \beta\right)
$$

Em geral, o modelo de Regressão Quantílica pode ser escrito como $y_{i}=x_{i}^{T} \beta+\varepsilon_{i}$, onde o termo de erro $\varepsilon_{i}$ pode ser decomposto em duas partes: $u_{i}$ para os erros que se encontram acima do quantil desejado e $v_{i}$ para os erros que estão abaixo dele. Desta forma temos que $\varepsilon_{i}=u_{i}-v_{i}$. Consequentemente, a solução para este problema é equivale a minimizar o termo de erro formado por $u$ e $v$, sujeito às restrições de não-negatividade para os erros e a satisfazer a condição $y_{i}=x_{i}^{T} \beta+\varepsilon_{i}$. Destaca-se que os $\beta$ são variáveis não restritas. Desta forma, o problema de Regressão Quantílica definido na Eq. (9) pode ser reformulado como um problema de programação linear como segue:

$$
\min _{\beta, u, v} \tau \sum_{i=1}^{n} u_{i}+(1-\tau) \sum_{i=1}^{n} v_{i}
$$

s.a.

$$
\begin{array}{ll}
y_{i}=x_{i}^{T} \beta+u_{i}-v_{i} & \forall i=1,2, \ldots, n \\
u_{i} \geq 0, v_{i} \geq 0 \quad v_{i} & \forall i=1,2, \ldots, n
\end{array}
$$

$$
\beta \in \mathbb{R}^{p}
$$

Onde os termos da função objetivo derivam-se da função de perda $\rho_{\tau}$.

A seguir, na seção 3, são discutidos os aspectos referentes ao conjunto de dados e as transformações necessárias para a aplicação da metodologia de Regressão Quantílica.

\section{CARACTERIZAÇÃO DA VELOCIDADE DO VENTO E DA GERAÇÃO EÓLICA}

A base de dados objeto de estudo deste trabalho, corresponde aos dados fornecidos por um parque eólico no Brasil para uma única turbina. O conjunto de dados contém registros horários durante o período de 01 de janeiro de 2016 até 01 de janeiro de 2017; i.e. um total de 8.784 médias horárias da velocidade do vento $(\mathrm{m} / \mathrm{s})$ e da produção eólica $(\mathrm{kWh})$ para uma turbina eólica com potência nominal de 2.200 kWh. Destas observações tomou-se uma amostra de 8.760 observações para serem usadas no processo de estimação dos modelos de Regressão Linear e Regressão Quantílica, e as 24 observações restantes foram utilizadas para obter as previsões da variável de resposta. Na Figura 1 é apresentado o diagrama de dispersão dos dados para o período anteriormente indicado. 


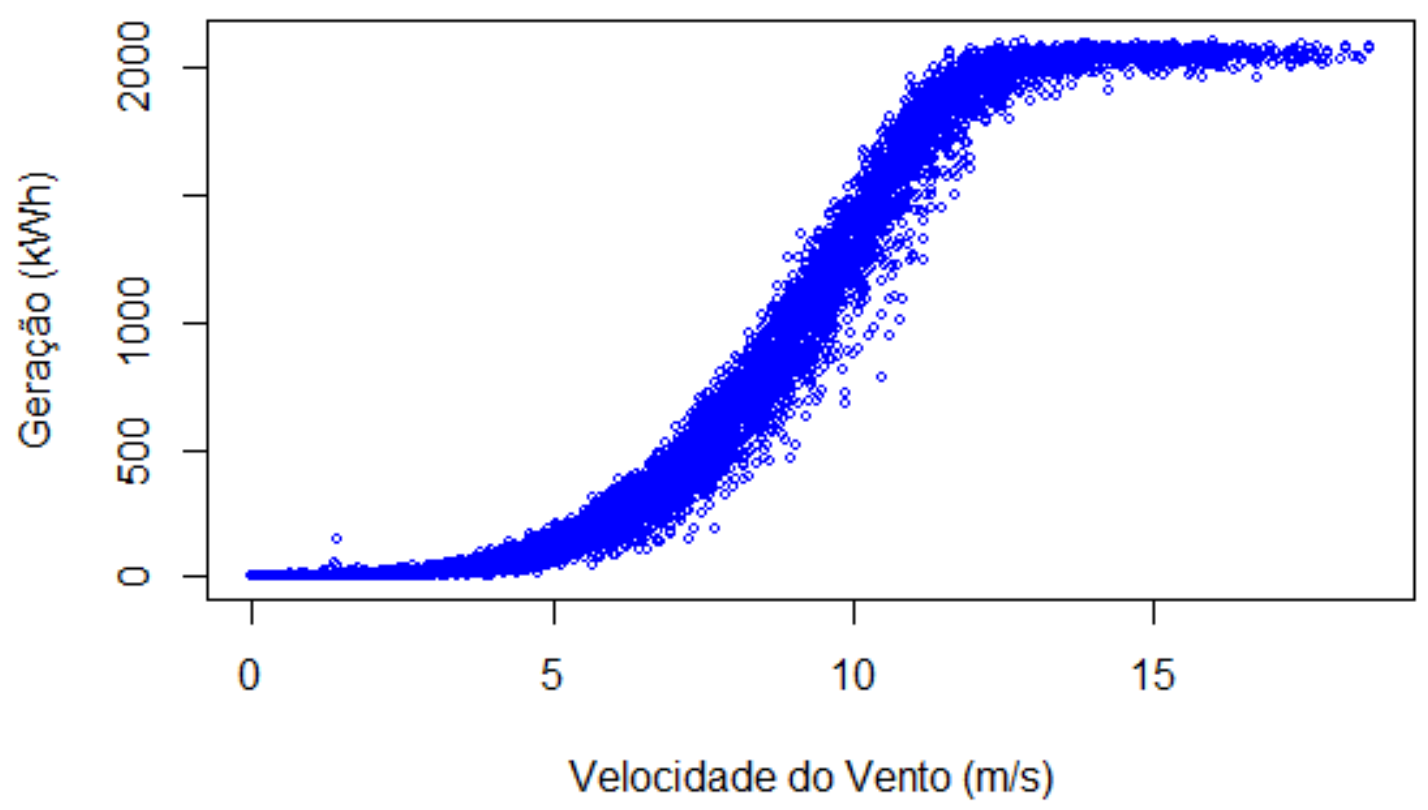

Figura 1. Curva de dispersão da velocidade do vento e a geração eólica.

A Figura 1 representa a tradicional curva de potência amostral. Um aspecto muito importante a ser destacado é que para uma mesma velocidade do vento existem diversos valores de geração como pode ser observado nesta Figura. De forma complementar à análise gráfica, na Tabela 1, são apresentados os resultados de análise descritiva tanto da velocidade do vento quanto da potência.

Tabela 1 - Análise descritiva

\begin{tabular}{lcc}
\hline & $\begin{array}{c}\text { Velocidade do vento } \\
(\mathbf{m} / \mathbf{s})\end{array}$ & $\begin{array}{c}\text { Geração } \\
\text { Eólica (kWh) }\end{array}$ \\
\hline Mínimo & 0,0007 & 0,00 \\
lero quartil & 3,5674 & 37,04 \\
Mediana & 6,7294 & 333,62 \\
Média & 6,9207 & 686,68 \\
3ero quartil & 9,9254 & $1.273,44$ \\
Máximo & 18,5910 & $2.100,56$ \\
\hline
\end{tabular}

No contexto de geração para uma única turbina, o domínio dos valores que assume a geração eólica está restringido ao intervalo entre zero e a capacidade da turbina. No entanto, no processo de otimização se admite que os coeficientes de regressão são irrestritos, pudendo consequentemente gerar quantis negativos ou acima da capacidade da turbina, se o processo de otimização para a estimação dos coeficientes de regressão for aplicado sobre os dados puros. Para superar esta limitação, a estratégia adotada é inicialmente normalizar os dados da geração eólica (Eq. (11)); e posteriormente, é aplicada uma transformação fazendo uso da função arco tangente hiperbólica, sobre os valores normalizados como indicado na Eq. (12). 


$$
\begin{gathered}
y_{t}^{*}=\frac{y_{t}-\min (y)}{\max (y)-\min (y)} \\
y_{t}^{* *}=0,5 \cdot \ln \left[\frac{1+y_{t}^{*}}{1-y_{t}^{*}}\right]
\end{gathered}
$$

Aplicando dita transformação ao conjunto de observações para ajuste dos modelos obtem-se um diagrama de dispersão como é apresentado na Figura 2, o qual relaciona a velocidade do vento e a transformação $y_{t}^{* *}$ da geração eólica.

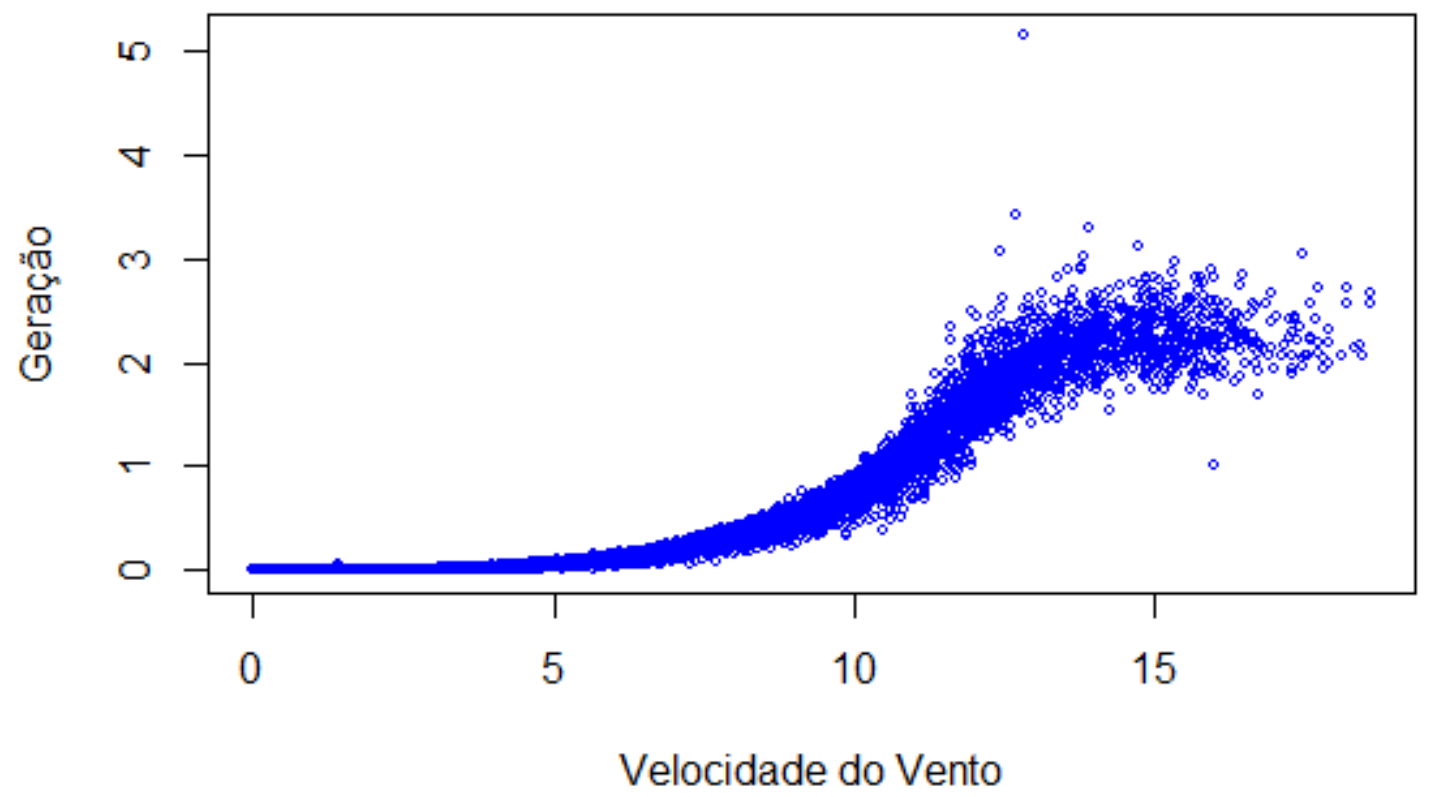

Figura 2. Curva de dispersão da velocidade do vento e a transformação da geração eólica.

Uma vez os quantis são estimados, é preciso que sejam escalados para o intervalo definido pelos valores mínimo e máximo da geração eólica como segue:

$$
\begin{gathered}
q^{*}=\frac{\exp (q)-\exp (-q)}{\exp (q)+\exp (-q)} \\
Q=[\max (y)-\min (y)] \cdot q^{*}+\min (y)
\end{gathered}
$$

Sendo $y$ a geração produzida para o quantil $q^{*}$ dada uma determinada velocidade.

Como consequência da relação não linear entre a velocidade do vento, como observado na Figura 2, optou-se por analisar segmentos do conjunto de observações, com o intuito de modelar os trechos que têm um comportamento mais linear. Desta forma, foram estabelecidos 6 conjuntos de dados segmentados pela velocidade do vento como é apresentado na Tabela 2 e na Figura 3. 
Tabela 2 - Segmentação da Velocidade do Vento

\begin{tabular}{cc}
\hline $\begin{array}{c}\text { Intervalos da } \\
\text { Velocidade do Vento }\end{array}$ & $\begin{array}{c}\text { Total de } \\
\text { observações }\end{array}$ \\
\hline$[0-2)$ & 1.224 \\
{$[2-4)$} & 1.257 \\
{$[4-7)$} & 2.077 \\
{$[7-9)$} & 1.413 \\
{$[9-11,5)$} & 1.378 \\
{$[11,5-19)$} & 1.411 \\
\hline Total & 8.760 \\
\hline
\end{tabular}

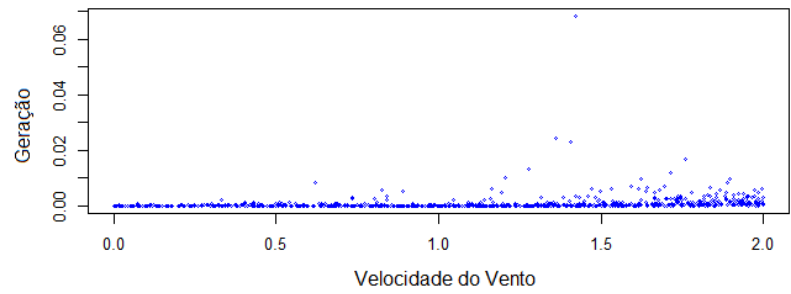

(a)

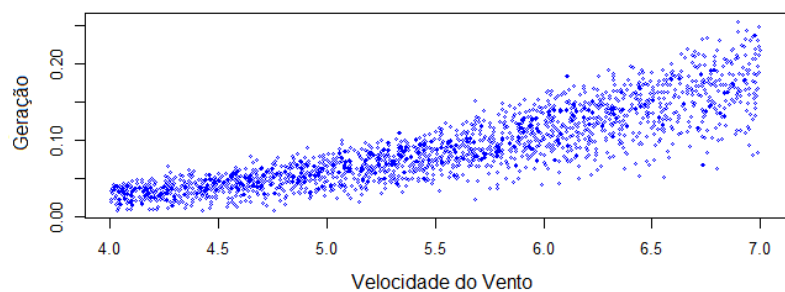

(c)

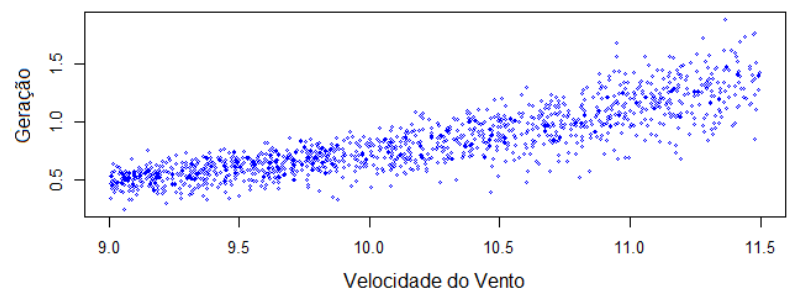

(e)

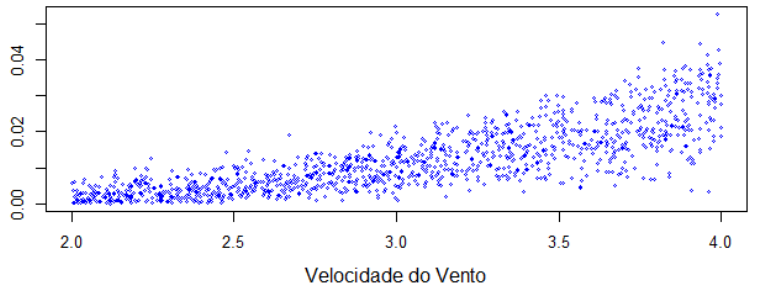

(b)

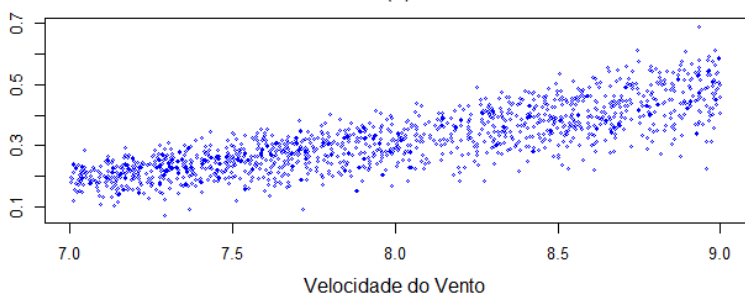

(d)

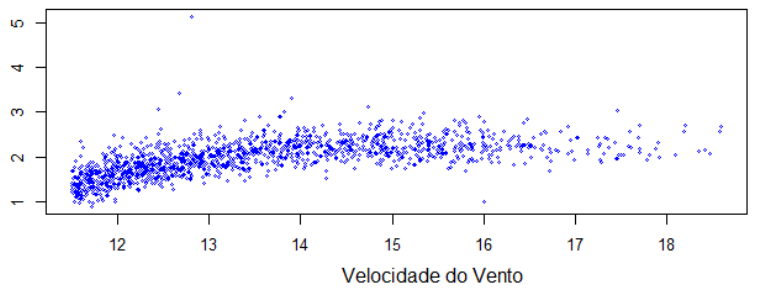

(f)

Figura 3. Curvas de dispersão para os intervalos: [0 - 2) (a), [2 - 4) (b), [ 4 - 7) (c), [7 - 9) (d), $[9-11,5)(e)$ e $[11,5-19)(f)$.

A modelagem de Regressão Quantílica será aplicada a cada novo conjunto de dados de cada intervalo da Tabela 2. Para isto, serão estimados os parâmetros para os 9 quantis $\tau=(0,01 ; 0,05 ; 0,10 ; 0,25 ; 0,5 ; 0,75 ; 0,90 ; 0,95 ; 0,99)$; além do modelo de Regressão Linear Simples que permite a comparação do valor esperado condicional com a mediana condicional. Em total são estimados 10 modelos de regressão. Na seção seguinte serão apresentados todos os resultados dos modelos ajustados junto com os resultados de previsão 24 horas à frente. 


\section{RESULTADOS}

Nesta seção serão apresentados os ajustes dos modelos de Regressão Quantílica para cada um dos 9 quantis indicados anteriormente, assim como o ajuste do modelo de Regressão Linear Simples que servirá de base comparativa entre ambas as metodologias. Desta forma, na Tabela 3 é apresentado o ajuste dos coeficientes de regressão da Eq. (3) para o primeiro conjunto de dados que relaciona a velocidade do vento que vá de [0 - 2) e a geração eólica. Como se ilustra na Figura 4, os dados possuem um nível muito perto de zero, razão pela o ajuste dos primeiros quatro quantis outorgar uma estimativa de zero para os parâmetros. Como era de se esperar, os quantis mais evidentes são os de 0,90, 0,95 e 0,99, os quais tem uma maior contribuição por parte das observações com maior magnitude. No entanto, o parâmetro do intercepto não é significativo tanto para estes quantis, quanto para o quantil de 0,75 . Em vermelho pode-se observar o ajuste para a regressão condicional da média, cujo parâmetro do intercepto também não é significativo.

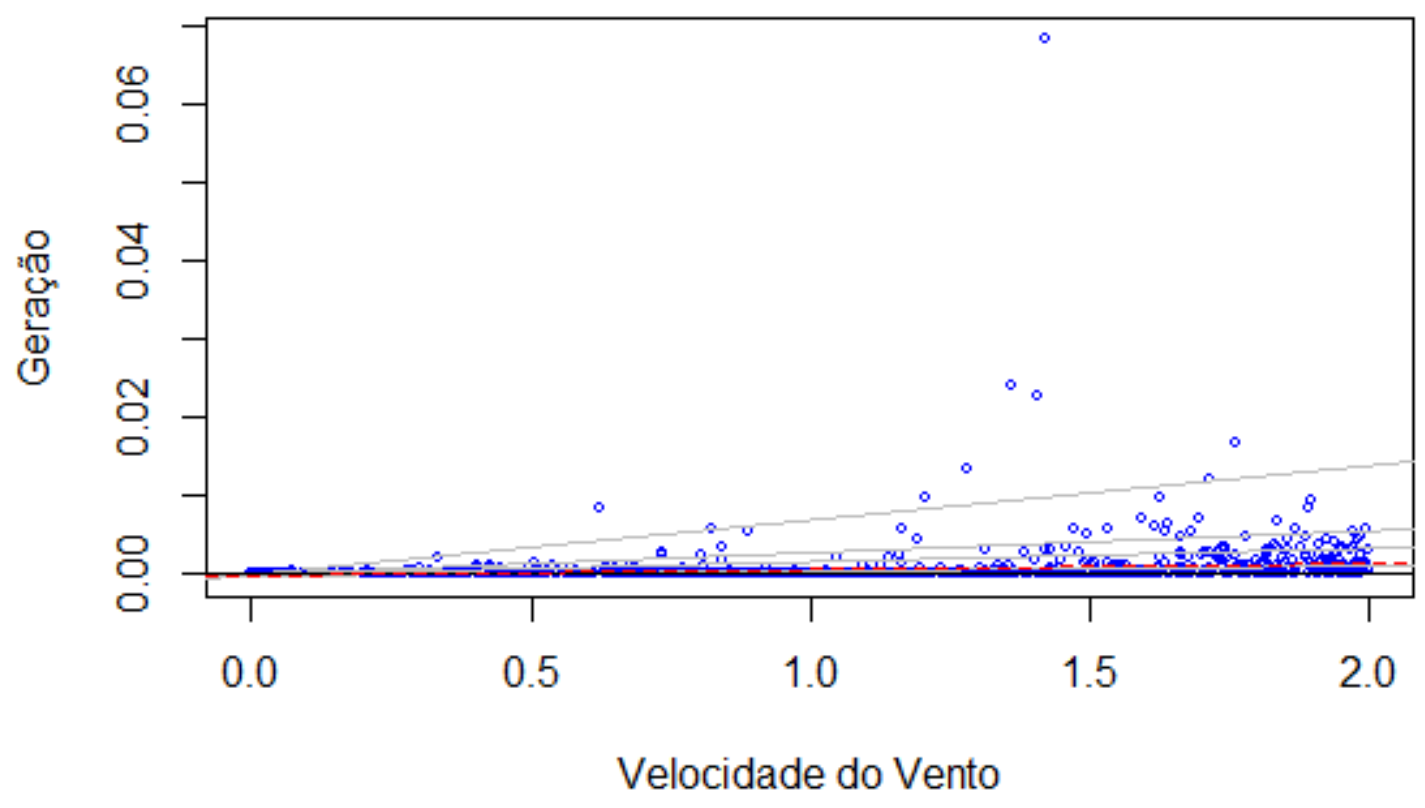

Figura 4. Ajuste dos modelos de Regressão Quantílica e Regressão Linear Simples para o conjunto de dados cuja velocidade está no intervalo [0 - 2).

De forma semelhante é produzido para os restantes conjuntos de dados. As Figuras 5 até 9 detalham as retas de ajuste quantílico para todos os quantis com exceção da mediana (quantil 0,5) que está colorido em preto. A linha vermelha corresponde ao ajuste da reta de um modelo de Regressão Linear Simples como indicado no parágrafo anterior.

Em relação ao ajuste dos modelos, as Tabelas 3, 4, 5, 6, 7 e 8 contém o valor estimados dos parâmetros dos modelos, nelas optou-se pelo traço como nomenclatura para indicar que para esse quantil ou modelo, a estimação do parâmetro não era estatisticamente significativa. Cabe ressaltar que estas tabelas que contém o ajuste tanto dos modelos de Regressão Quantílica quanto de Regressão Linear Simples. As previsões da geração eólica são geradas para 24 horas à frente utilizam a velocidade do vento realizada neste intervalo de tempo e os parâmetros dos modelos ajustados, cujos resultados são apresentados na Tabela 9. 


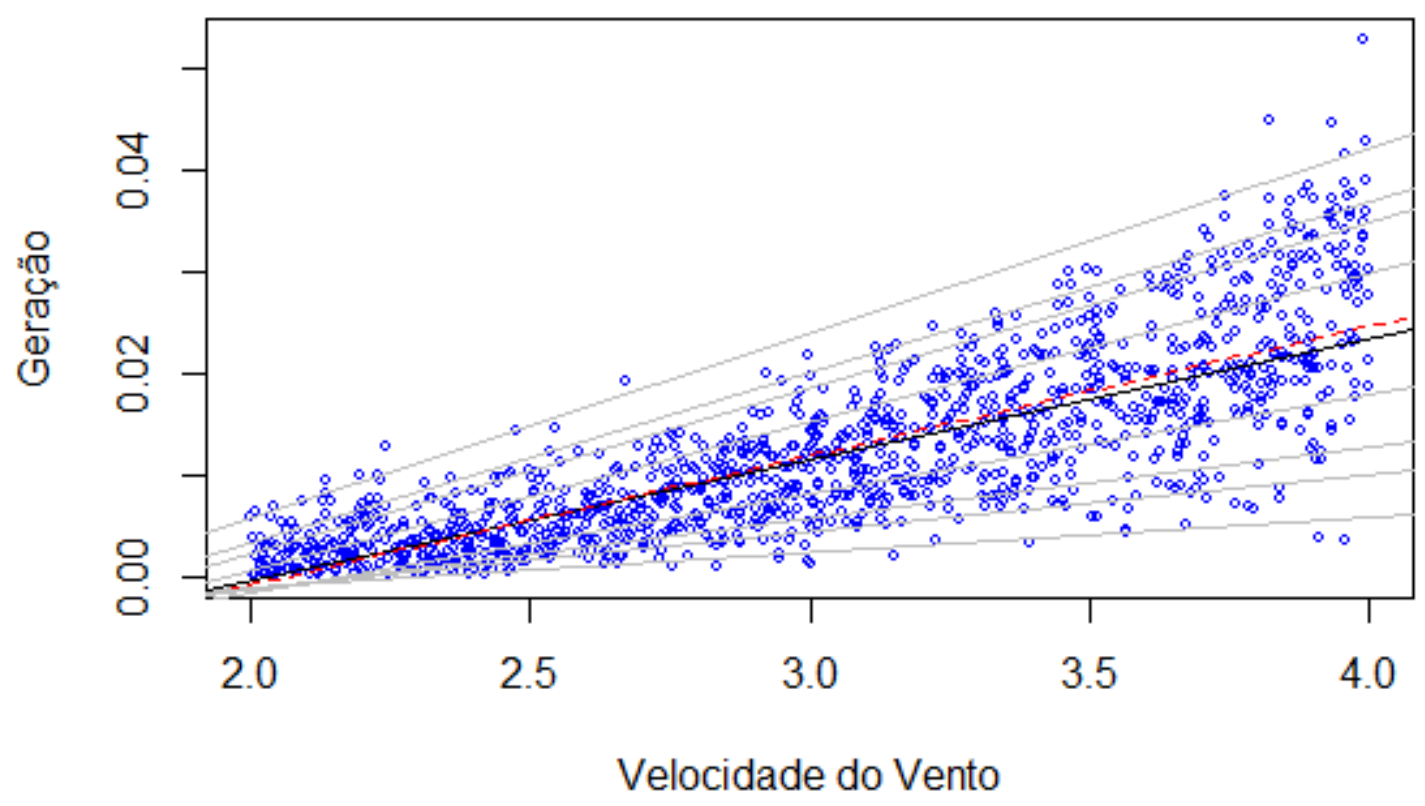

Figura 5. Ajuste dos modelos de Regressão Quantílica e Regressão Linear Simples para o conjunto de dados cuja velocidade está no intervalo [2 -4).

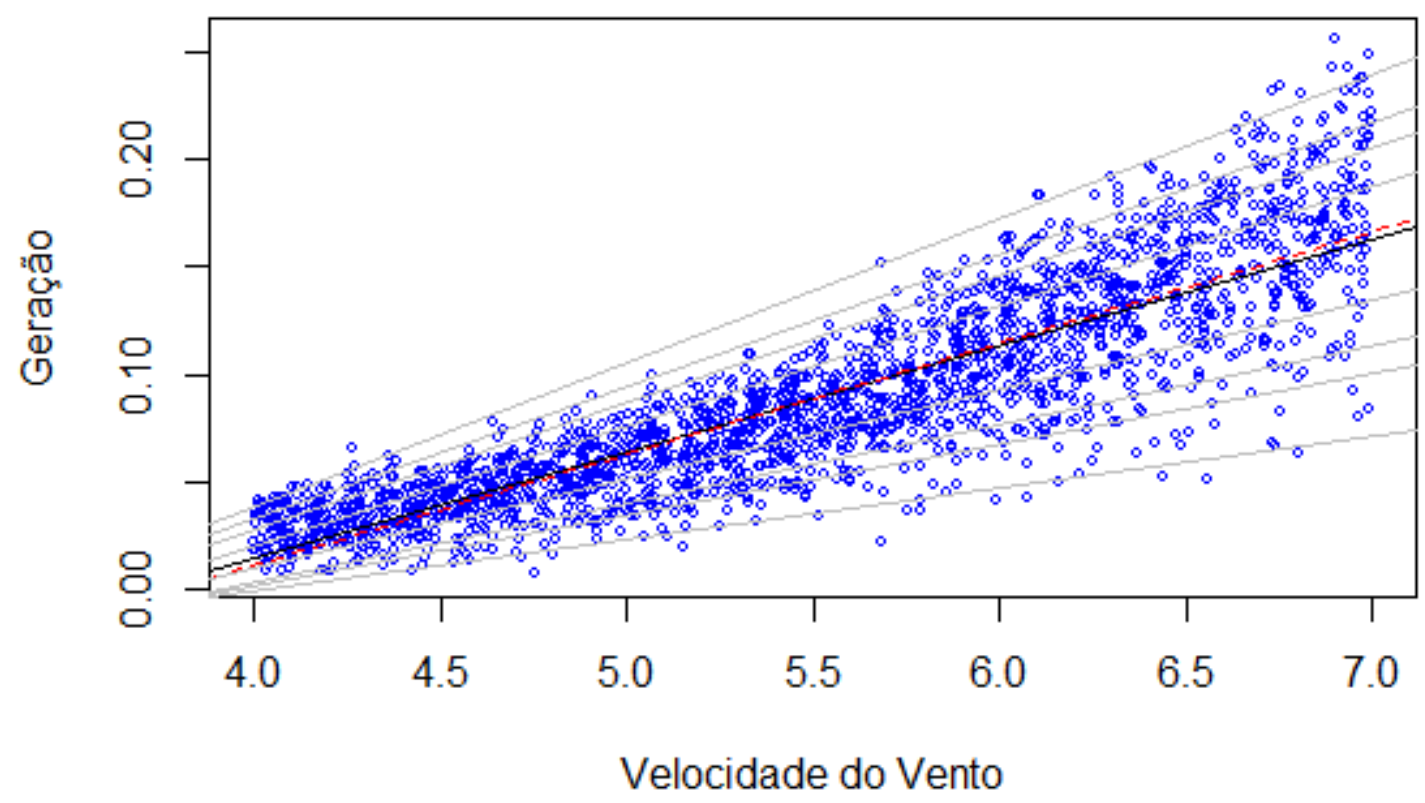

Figura 6. Ajuste dos modelos de Regressão Quantílica e Regressão Linear Simples para o conjunto de dados cuja velocidade está no intervalo [4 - 7). 
Tabela 3 - Estimações de Regressão Quantílica e Regressão Linear Simples para a geração eólica, no conjunto de dados da velocidade [0 - 2).

\begin{tabular}{c|cccccccccc}
\hline \multirow{2}{*}{ Parâmetros } & $\mathbf{0}, \mathbf{9}$ Regressão Quantílica & \multicolumn{1}{c}{ R. Linear } \\
& $\mathbf{0 , 0 1}$ & $\mathbf{0 , 0 5}$ & $\mathbf{0 , 1}$ & $\mathbf{0 , 2 5}$ & $\mathbf{0 , 5}$ & $\mathbf{0 , 7 5}$ & $\mathbf{0 , 9 0}$ & $\mathbf{0 , 9 5}$ & $\mathbf{0 , 9 9}$ & Simples \\
\hline $\boldsymbol{\beta}_{\mathbf{0}}$ & 0,00000 & 0,00000 & 0,00000 & 0,00000 & 0,00001 & - & - & - & - & - \\
Erro padrão & 0,00000 & 0,00000 & 0,00000 & 0,00000 & 0,00000 & - & - & - & - & - \\
\hline $\boldsymbol{\beta}_{\mathbf{1}}$ & 0,00000 & 0,00000 & 0,00000 & 0,00001 & 0,00011 & 0,00060 & 0,00174 & 0,00274 & 0,00703 & $7,432 \mathrm{e}-04$ \\
Erro padrão & 0,00000 & 0,00000 & 0,00000 & 0,00000 & 0,00002 & 0,00000 & 0,00015 & 0,00032 & 0,00317 & $6,648 \mathrm{e}-05$ \\
\hline
\end{tabular}

Tabela 4 - Estimações de Regressão Quantílica e Regressão Linear Simples para a geração eólica, no conjunto de dados da velocidade [2 - 4).

\begin{tabular}{|c|c|c|c|c|c|c|c|c|c|c|}
\hline \multirow{2}{*}{ Parâmetros } & \multicolumn{9}{|c|}{ Regressão Quantílica } & \multirow{2}{*}{$\begin{array}{c}\text { R, Linear } \\
\text { Simples }\end{array}$} \\
\hline & 0,01 & 0,05 & 0,1 & 0,25 & 0,5 & 0,75 & 0,90 & 0,95 & 0,99 & \\
\hline$\beta_{0}$ & $-0,00780$ & $-0,01268$ & $-0,01541$ & $-0,02109$ & $-0,02404$ & $-0,02867$ & $-0,03034$ & $-0,03021$ & $-0,03070$ & 0,02662 \\
\hline Erro padrão & 0,00128 & 0,00064 & 0,00062 & 0,00067 & 0,00072 & 0,00100 & 0,00096 & 0,00145 & 0,00267 & 0,00080 \\
\hline$\beta_{1}$ & 0,00338 & 0,00568 & 0,00700 & 0,00975 & 0,01184 & 0,01464 & 0,01629 & 0,01677 & 0,01820 & 0,01281 \\
\hline Erro padrão & 0,00055 & 0,00028 & 0,00028 & 0,00028 & 0,00028 & 0,00037 & 0,00035 & 0,00049 & 0,00112 & 0,00026 \\
\hline
\end{tabular}

Tabela 5 - Estimações de Regressão Quantílica e Regressão Linear Simples para a geração eólica, no conjunto de dados da velocidade [4 - 7).

\begin{tabular}{|c|c|c|c|c|c|c|c|c|c|c|}
\hline \multirow{2}{*}{ Parâmetros } & \multicolumn{9}{|c|}{ Regressão Quantílica } & \multirow{2}{*}{$\begin{array}{c}\text { R, Linear } \\
\text { Simples }\end{array}$} \\
\hline & 0,01 & 0,05 & 0,1 & 0,25 & 0,5 & 0,75 & 0,90 & 0,95 & 0,99 & \\
\hline$\beta_{0}$ & $-0,09548$ & $-0,12786$ & $-0,14343$ & $-0,15550$ & $-0,18264$ & $-0,20238$ & $-0,20991$ & $-0,21284$ & $-0,22957$ & $-0,19458$ \\
\hline Erro padrão & 0,00835 & 0,00355 & 0,00524 & 0,00322 & 0,00350 & 0,00388 & 0,00517 & 0,00672 & 0,00721 & 0,00346 \\
\hline$\beta_{1}$ & 0,02387 & 0,03258 & 0,03677 & 0,04152 & 0,04936 & 0,05571 & 0,05936 & 0,06140 & 0,06700 & 0,05147 \\
\hline Erro padrão & 0,00180 & 0,00087 & 0,00106 & 0,00068 & 0,00072 & 0,00076 & 0,00100 & 0,00133 & 0,00151 & 0,00062 \\
\hline
\end{tabular}




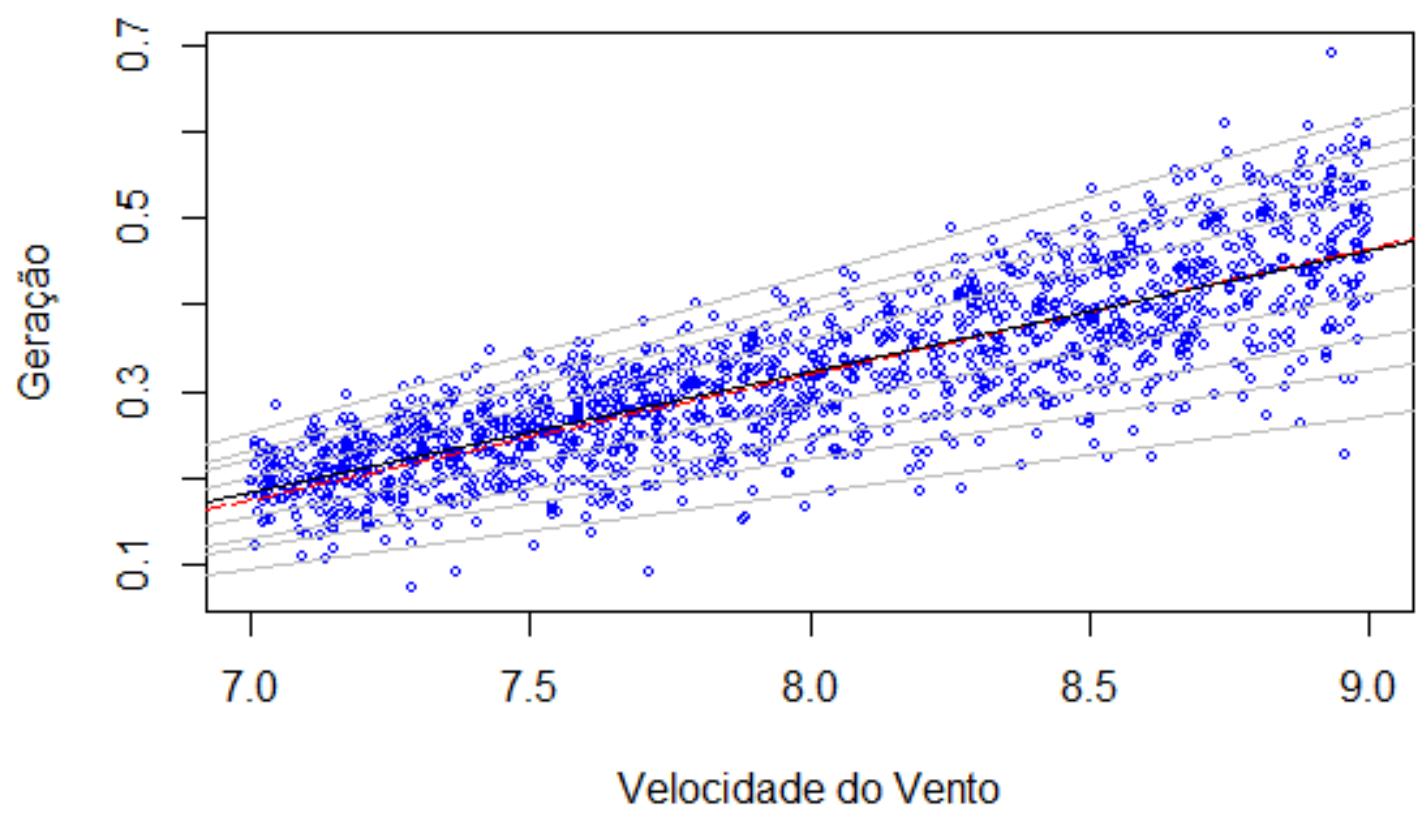

Figura 7. Ajuste dos modelos de Regressão Quantílica e Regressão Linear Simples para o conjunto de dados cuja velocidade está no intervalo [7 - 9).

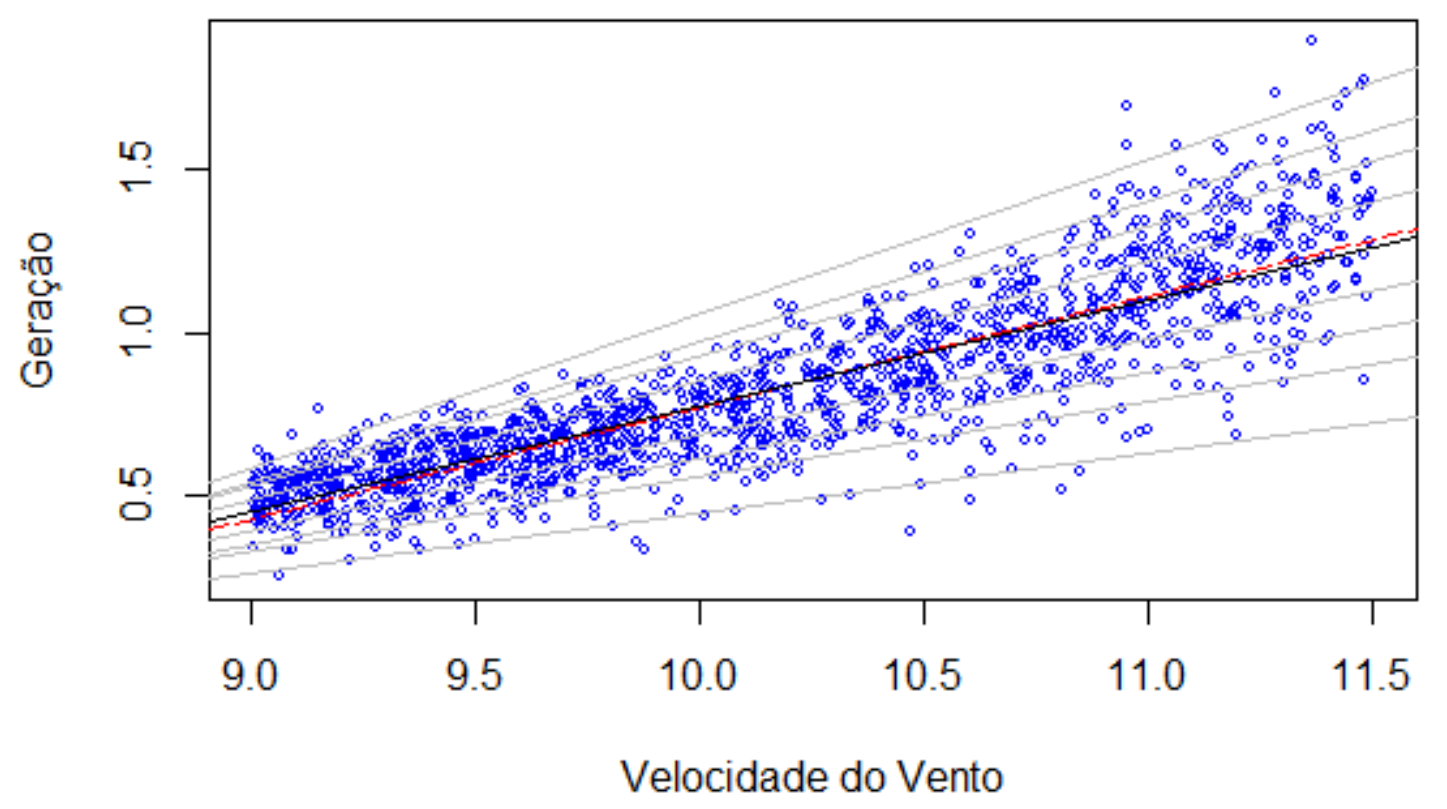

Figura 8. Ajuste dos modelos de Regressão Quantílica e Regressão Linear Simples para o conjunto de dados cuja velocidade está no intervalo [9 - 11.5). 
Tabela 6 - Estimações de Regressão Quantílica e Regressão Linear Simples para a geração eólica, no conjunto de dados da velocidade [7 - 9).

\begin{tabular}{c|cccccccccc}
\hline & \multicolumn{9}{c}{ Regressão Quantilica } & \multicolumn{1}{c}{ R. Linear } \\
Parâmetros & $\mathbf{0 , 0 1}$ & $\mathbf{0 , 0 5}$ & $\mathbf{0 , 1}$ & $\mathbf{0 , 2 5}$ & $\mathbf{0 , 5}$ & $\mathbf{0 , 7 5}$ & $\mathbf{0 , 9 0}$ & $\mathbf{0 , 9 5}$ & $\mathbf{0 , 9 9}$ & Simples \\
\hline $\boldsymbol{\beta}_{\mathbf{0}}$ & $-0,52953$ & $-0,60377$ & $-0,68507$ & $-0,75080$ & $-0,80042$ & $-0,93069$ & $-0,94822$ & $-0,99252$ & $-1,02849$ & $-0,84033$ \\
Erro padrão & 0,10258 & 0,04932 & 0,03547 & 0,02970 & 0,02336 & 0,02356 & 0,02976 & 0,03066 & 0,05465 & 0,02061 \\
\hline $\boldsymbol{\beta}_{\mathbf{1}}$ & 0,08893 & 0,10320 & 0,11621 & 0,12924 & 0,14041 & 0,16166 & 0,16723 & 0,17486 & 0,18288 & 0,14510 \\
Erro padrão & 0,01259 & 0,00635 & 0,00457 & 0,00377 & 0,00304 & 0,00305 & 0,00375 & 0,00399 & 0,00686 & 0,00257 \\
\hline
\end{tabular}

Tabela 7 - Estimações de Regressão Quantílica e Regressão Linear Simples para a geração eólica, no conjunto de dados da velocidade [9 - 11,5).

\begin{tabular}{|c|c|c|c|c|c|c|c|c|c|c|}
\hline \multirow{2}{*}{ Parâmetros } & \multicolumn{9}{|c|}{ Regressão Quantílica } & \multirow{2}{*}{$\begin{array}{c}\text { R, Linear } \\
\text { Simples }\end{array}$} \\
\hline & 0,01 & 0,05 & 0,1 & 0,25 & 0,5 & 0,75 & 0,90 & 0,95 & 0,99 & \\
\hline $\boldsymbol{\beta}_{0}$ & $-1,37500$ & $-1,69703$ & $-1,99918$ & $-2,25491$ & $-2,45770$ & $-2,77674$ & $-3,04228$ & $-3,31113$ & $-3,64930$ & $-2,64120$ \\
\hline Erro padrão & 0,28185 & 0,13225 & 0,08248 & 0,07094 & 0,06221 & 0,05772 & 0,07367 & 0,12570 & 0,26584 & 0,05317 \\
\hline$\beta_{1}$ & 0,18236 & 0,22599 & 0,26154 & 0,29447 & 0,32330 & 0,36321 & 0,39704 & 0,42818 & 0,47084 & 0,34105 \\
\hline Erro padrão & 0,02931 & 0,01367 & 0,00848 & 0,00718 & 0,00638 & 0,00593 & 0,00758 & 0,01307 & 0,02690 & 0,00522 \\
\hline
\end{tabular}

Tabela 8 - Estimações de Regressão Quantílica e Regressão Linear Simples para a geração eólica, no conjunto de dados da velocidade [11,5 - 19).

\begin{tabular}{c|cccccccccc}
\hline \multirow{2}{*}{ Parâmetros } & $\mathbf{0}, \mathbf{0 1}$ & $\mathbf{0 , 0 5}$ & $\mathbf{0 , 1}$ & $\mathbf{0 , 2 5}$ & $\mathbf{0 , 5}$ & $\mathbf{0 , 7 5}$ & $\mathbf{0 , 9 0}$ & $\mathbf{0 , 9 5}$ & $\mathbf{0 , 9 9}$ & R, Linear \\
& $\mathbf{0 , 0 1}$ & $-0,38458$ & $-0,37343$ & $-0,40491$ & $-0,22752$ & $-0,19100$ & - & 0,38426 & 1,29088 & - \\
\hline $\boldsymbol{\beta}_{\mathbf{0}}$ & $-0,70539$ & $-0,38458$ & - \\
Erro padrão & 0,18855 & 0,14274 & 0,11576 & 0,08687 & 0,08997 & 0,08205 & - & 0,14085 & 0,60290 & - \\
\hline $\boldsymbol{\beta}_{\mathbf{1}}$ & 0,15037 & 0,13936 & 0,14551 & 0,16072 & 0,16113 & 0,17335 & 0,17287 & 0,15365 & 0,10313 & 0,14571 \\
Erro padrão & 0,01343 & 0,01062 & 0,00866 & 0,00632 & 0,00673 & 0,00600 & 0,00132 & 0,01043 & 0,03717 & 0,00060 \\
\hline
\end{tabular}




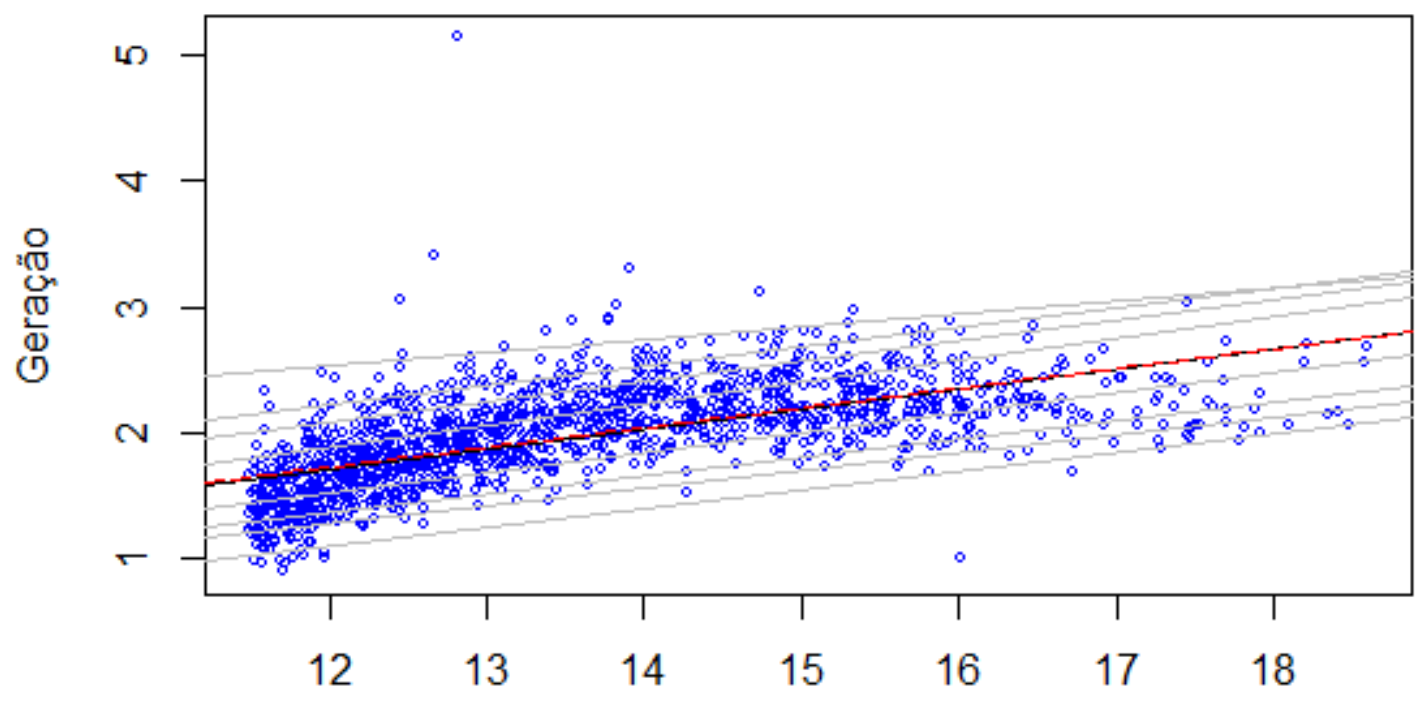

\section{Velocidade do Vento}

Figura 9. Ajuste dos modelos de Regressão Quantílica e Regressão Linear Simples para o conjunto de dados cuja velocidade está no intervalo [11,5 $-<19)$.

Tabela 9 - Previsão da Geração Eólica para 24 horas à frente.

\begin{tabular}{|c|c|c|c|c|c|c|c|c|c|c|c|c|}
\hline \multirow{2}{*}{ Quantis } & \multicolumn{12}{|c|}{ Geração Eólica Real - Hora = 1 até $12(\mathrm{kWh})$} \\
\hline & 1969,3 & 1951,6 & 1906,2 & 529,2 & 317,3 & 366,7 & 342,3 & 134,3 & 30,4 & 34,1 & 41,2 & 124,2 \\
\hline 0,01 & $1.713,7$ & $1.734,3$ & $1.147,0$ & 414,0 & 115,2 & 135,2 & 125,2 & 85,2 & 7,0 & 10,0 & 11,3 & 65,2 \\
\hline 0,05 & $1.825,7$ & $1.839,7$ & $1.354,3$ & 499,6 & 162,2 & 189,4 & 175,8 & 121,4 & 12,7 & 18,9 & 19,9 & 94,1 \\
\hline 0,1 & $1.867,1$ & $1.879,6$ & $1.453,4$ & 549,6 & 184,8 & 215,4 & 200,2 & 138,8 & 16,2 & 23,1 & 25,0 & 108,0 \\
\hline 0,25 & $1.926,9$ & $1.937,3$ & $1.558,5$ & 629,1 & 222,0 & 256,4 & 239,2 & 170,1 & 23,3 & 39,7 & 35,6 & 135,4 \\
\hline 0,5 & $\underline{1.978,5}$ & $\underline{1.985,9}$ & $\underline{1.655,4}$ & $\underline{708,3}$ & $\underline{268,1}$ & $\underline{308,8}$ & $\underline{288,5}$ & $\underline{206,7}$ & $\underline{31,6}$ & $\underline{51,8}$ & $\underline{46,5}$ & $\underline{165,5}$ \\
\hline 0,75 & $2.015,8$ & $2.021,3$ & $1.739,6$ & $\overline{789,0}$ & $\overline{309,9}$ & 355,5 & 332,7 & $\overline{240,9}$ & 41,3 & $\overline{66,4}$ & 59,7 & 194,5 \\
\hline 0,9 & $2.041,6$ & $2.045,5$ & $1.802,1$ & 839,2 & 341,6 & 389,9 & 365,8 & 268,3 & 49,2 & 82,7 & 69,7 & 219,1 \\
\hline 0,95 & $2.056,6$ & $2.059,2$ & $1.839,0$ & 871,2 & 361,8 & 411,7 & 386,8 & 286,3 & 52,8 & 94,5 & 73,9 & 235,5 \\
\hline 0,99 & $2.075,6$ & $2.076,6$ & $1.894,7$ & 922,4 & 399,5 & 453,5 & 426,6 & 317,5 & 61,7 & 108,8 & 84,6 & 262,3 \\
\hline RL & $1.987,1$ & $1.993,4$ & $1.663,2$ & 705,6 & 270,9 & 313,3 & 292,1 & 206,9 & 144,5 & 45,4 & 160,5 & 164,0 \\
\hline
\end{tabular}

\begin{tabular}{rrrrrrrrrrrrrr}
\hline \multirow{2}{*}{ Quantis } & $\mathbf{8}$ & \multicolumn{10}{c}{ Geração Eólica Real - Hora $=\mathbf{1 2}$ até $\mathbf{2 4} \mathbf{( k W h )}$} \\
& $\mathbf{7 8 , 5}$ & $\mathbf{8 6 , 8}$ & $\mathbf{9 , 2}$ & $\mathbf{5 , 6}$ & $\mathbf{1 , 8}$ & $\mathbf{1 5 , 1}$ & $\mathbf{1 , 1}$ & $\mathbf{2 6 6 , 7}$ & $\mathbf{1 7 9 5 , 0}$ & $\mathbf{2 0 8 6 , 9}$ & $\mathbf{2 0 5 5 , 2}$ & $\mathbf{2 0 1 2 , 5}$ \\
\hline $\mathbf{0 , 0 1}$ & 15,0 & 25,1 & 0,7 & 0,0 & 0,0 & 0,1 & 0,0 & 120,2 & $1.633,1$ & $2.010,6$ & $1.999,4$ & $1.968,9$ \\
$\mathbf{0 , 0 5}$ & 25,7 & 39,4 & 2,0 & 0,0 & 0,0 & 0,8 & 0,0 & 169,0 & $1.771,1$ & $2.030,8$ & $2.022,7$ & $2.001,0$ \\
$\mathbf{0 , 1}$ & 30,8 & 46,3 & 2,9 & 0,0 & 0,0 & 1,4 & 0,0 & 192,5 & $1.817,8$ & $2.045,3$ & $2.038,5$ & $2.020,3$ \\
$\mathbf{0 , 2 5}$ & 48,4 & 65,8 & 4,9 & 0,0 & 0,0 & 2,8 & 0,0 & 230,6 & $1.885,3$ & $2.065,7$ & $2.061,0$ & $2.047,8$ \\
$\mathbf{0 , 5}$ & $\underline{\mathbf{6 2 , 2}}$ & $\underline{\mathbf{8 2 , 9}}$ & $\underline{\mathbf{9 , 2}}$ & $\underline{\mathbf{0 , 4}}$ & $\underline{\mathbf{0 , 3}}$ & $\underline{\mathbf{6 , 7}}$ & $\underline{\mathbf{1 , 7}}$ & $\underline{\mathbf{2 7 8 , 3}}$ & $\mathbf{1 . 9 4 8 , 7}$ & $\mathbf{2 . 0 7 6 , 4}$ & $\mathbf{2 . 0 7 3 , \mathbf { 1 }}$ & $\underline{\mathbf{2 . 0 6 3 , 9}}$ \\
$\mathbf{0 , 7 5}$ & 78,0 & 101,4 & 13,6 & 2,1 & 1,6 & 10,5 & 4,4 & 321,3 & $1.993,1$ & $2.085,8$ & $2.083,7$ & $2.077,5$ \\
$\mathbf{0 , 9}$ & 95,2 & 120,0 & 18,4 & 6,2 & 4,8 & 15,0 & 8,1 & 353,7 & $2.025,8$ & $2.090,3$ & $2.088,8$ & $2.084,6$ \\
$\mathbf{0 , 9 5}$ & 107,4 & 133,1 & 21,1 & 9,8 & 7,5 & 17,6 & 10,5 & 374,3 & $2.046,1$ & $2.091,3$ & $2.090,1$ & $2.086,8$ \\
$\mathbf{0 , 9 9}$ & 122,8 & 150,8 & 27,3 & 25,1 & 19,2 & 23,4 & 15,8 & 413,0 & $2.071,7$ & $2.091,8$ & $2.091,1$ & $2.089,1$ \\
$\mathbf{R L}$ & 56,2 & 77,8 & 120,4 & 2,7 & 2,0 & 117,7 & 112,3 & 281,5 & $1.962,3$ & $2.074,4$ & $2.071,1$ & $2.062,4$ \\
\hline
\end{tabular}


Como pode ser observado na Tabela 9, as melhores previsões (ressaltadas em cinza) mostram um alta acurácia ao serem comparadas com o valor real, já que pelo menos $75 \%$ das previsões encontrava-se entre o quantil 0,25 e 0,75 , sendo mediana (55\%) o quantil que forneceu o maior número de previsões mais próximas do valor real.

\section{CONCLUSÕES}

Este trabalho apresenta uma abordagem simplificada para a previsão da geração de energia eólica via Regressão Quantílica. Para tal efeito, é preciso fazer uso da segmentação dos dados, além das equações de Regressão Quantílica que associam a velocidade do vento e produção eólica em cada quantil. Desta forma, são obtidos valores de previsão para cada quantil do intervalo especificado. Estes valores são comparados com a previsão do modelo de Regressão Lineal Simples que fornece a previsão da média condicional. Os resultados são satisfatórios uma vez que o modelo quantílico fornece uma visão da variabilidade da geração eólica, além das previsões serem mais precisas se comparado com modelo de Regressão Linear Simples. Como estudos posteriores podem ser futuramente analisadas abordagens que considerem a não linearidade da geração e a velocidade do vento, além de serem estendidas as análises para todas as turbinas de um parque eólico.

\section{AGRADECIMENTOS}

Os autores gostariam de agradecer o suporte financeiro outorgado pela FAPERJ/CAPES (projeto de pesquisa E-26 / 202.168 / 2015).

\section{REFERÊNCIAS BIBLIOGRÁFICAS}

[1] GWEC. Global wind report 2018. Global Wind Energy Council, Bruxelas, Bélgica, Reporte técnico. Disponível em: <https://gwec.net/wpcontent/uploads/2019/04/GWEC-Global-Wind-Report-2018.pdf>. Acesso em: 08 abr. 2019.

[2] WILLIAMS, James H. et al. The technology path to deep greenhouse gas emissions cuts by 2050: the pivotal role of electricity. Science, v. 335, n. 6064, p. 53-59, 2012.

[3] SURYAWANSHI, Anup; GHOSH, Debraj. Wind speed prediction using spatiotemporal covariance. Natural Hazards, v. 75, n. 2, p. 1435-1449, 2015.

[4] VARGAS, Soraida Aguilar et al. Wind power generation: a review and a research agenda. Journal of Cleaner Production, v. 218, n. 1, p. 850-870, 2019.

[5] KOENKER, Roger; BASSETT JR., Gilbert. Regression quantiles. Econometrica: Journal of the Econometric Society, v. 46, n. 1, p. 33-50, 1978.

[6] KOENKER, Roger. Quantile Regression. Cambridge University Press, 2005.

[7] HAO, Lingxin; NAIMAN, Daniel Q.; NAIMAN, Daniel Q. Quantile regression. Series: Quantitative Applications in the Social Sciences. Sage, 149, 2007. 